\title{
Review: a single dose of oral naproxen or naproxen sodium reduced acute postoperative pain in adults
}

Mason L, Edwards JE, Moore RA, et al. Single dose oral naproxen and naproxen sodium for acute postoperative pain. Cochrane Database Syst Rev 2004;(4):CD004234.

\section{$Q$ Is a single dose of oral naproxen or naproxen sodium effective and safe for acute postoperative pain in adults?}

\section{METHODS}

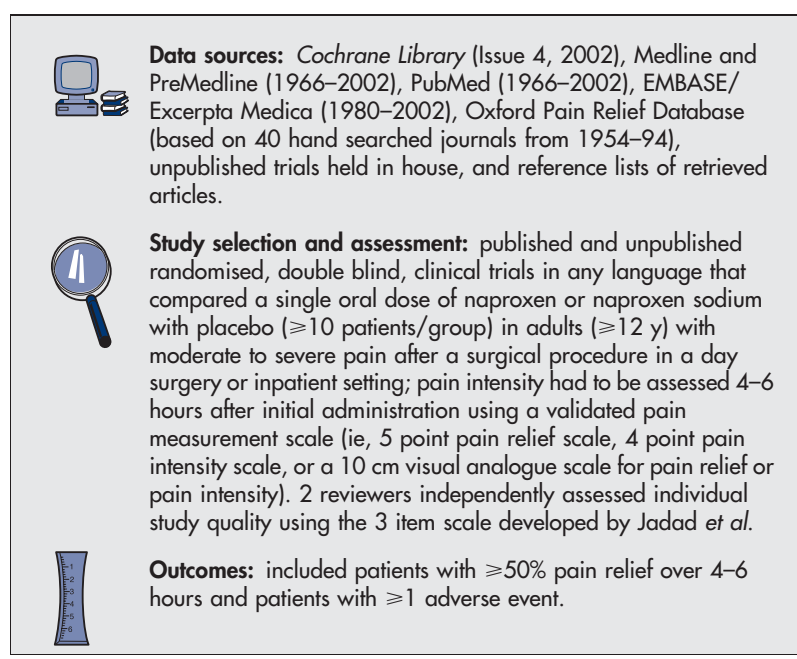

\section{MAIN RESULTS}

10 trials $(n=996$, age range $14-72$ y) met the selection criteria. $68 \%$ of patients had dental surgery, and the remaining patients had either orthopaedic or general surgery. All trials had quality scores $\geqslant 3$ out of 5. Meta-analysis was done using a fixed effects model and intention to treat data. More patients who received naproxen sodium, $550 \mathrm{mg}$, $440 \mathrm{mg}$, or $220 \mathrm{mg}$, or naproxen, $400 \mathrm{mg}$ or $200 \mathrm{mg}$, had $\geqslant 50 \%$ pain relief at 4-6 hours after surgery compared with placebo (table). Naproxen sodium, $550 \mathrm{mg}$, did not differ from placebo for number of patients reporting $\geqslant 1$ adverse event (table).

\section{CONCLUSION}

A single dose of oral naproxen sodium, $550 \mathrm{mg}$ (equivalent to naproxen, $500 \mathrm{mg}$ ) or $440 \mathrm{mg}$ (equivalent to naproxen, $400 \mathrm{mg}$ ), reduced acute postoperative pain in adults more than placebo.

For correspondence: Dr R A Moore, c/o Pain Research Unit, Churchill Hospital, Oxford, UK. andrew.moore@pru.ox.ac.uk

Source of funding: Oxford Pain Relief Trust.
Commentary

ain remains undertreated in postoperative settings' despite evidence of the effectiveness of specific treatments. In determining the efficacy, duration of action, and adverse effects of naproxen, a commonly prescribed non-steroidal anti-inflammatory drug (NSAID), the review by Mason et al presents clinicians with an alternative treatment to opioids for moderate to severe postoperative pain. The review addresses concerns about respiratory depression and impaired gastric motility associated with opioids. ${ }^{2}$ In considering this alternative, however, clinicians need to balance the benefits of opiate-sparing effects and the possibility of adverse effects.

Individuals have varying pain tolerances and may respond dissimilarly to different NSAIDs. The review provides comprehensive information on the effects of a single dose of naproxen or naproxen sodiuminformation that will be useful to clinicians managing patients who fail to respond to other prescribed NSAIDs or are prescribed lower or higher doses of naproxen or naproxen sodium.

Importantly, the meta-analyses showed significant pain relief with single dose usage. As well, the weighted mean time to remedication was 7.5 hours with naproxen sodium, $550 \mathrm{mg}$, compared with 2.6 hours with placebo. During heavy clinical workloads, less frequent medication requirements could help nurses to improve pain management and benefit patients who often wait for long periods after assessment for administration of pain medication. Although it is not uncommon to use a cut point of $50 \%$ pain relief in analyses of treatment effects, nurses should remember the subjective nature of pain and the potential negative effects of lower levels of pain on activities of daily living in some patients with lower pain thresholds. This again underscores the need for individual pain assessment.

The systematic review by Mason et al also highlights the inadequacy of available data on adverse events. Future studies of pain management need to include clear detailed reporting of patient withdrawals by treatment group.

Tracey Bucknall, RN, PhD University of Melbourne Melbourne, Victoria, Australia

1 Dolin SJ, Cashman JN, Bland JM. Br J Anaesth 2002;89:409-23.

2 British National Formulary. № 48. September 2004. http://www.bnf.org/ $\mathrm{bnf} / \mathrm{bnf} / 48 / /$ openat $/$ search.htm? $\mathrm{b}=2 \& q=\% 22$ opioids\%22. Accessed 14 January 2005.

Naproxen sodium (NapS) or naproxen (Nap) v placebo for acute postoperative pain in adults*

\begin{tabular}{|c|c|c|c|c|c|}
\hline $\begin{array}{l}\text { Outcome at } \\
4-6 \text { hours }\end{array}$ & $\begin{array}{l}\text { Number of } \\
\text { trials }(n)\end{array}$ & Drug and dosage & $\begin{array}{l}\text { Weighted event rates } \\
\text { (NapS/Nap v placebo) }\end{array}$ & RBI $(95 \% \mathrm{Cl})$ & NNT (Cl) \\
\hline \multirow[t]{2}{*}{$\geqslant 50 \%$ pain relief } & $\begin{array}{l}6(n=500) \\
3(n=334) \\
2(n=202)\end{array}$ & $\begin{array}{l}\text { NapS, } 550 \mathrm{mg} \\
\text { NapS/Nap, } 440 / 400 \mathrm{mg} \\
\text { NapS/Nap, } 220 / 200 \mathrm{mg}\end{array}$ & $\begin{array}{l}50 \% \vee 12 \% \\
50 \% \vee 11 \% \\
44 \% \vee 16 \%\end{array}$ & $\begin{array}{l}318 \%(193 \text { to } 497) \\
380 \%(175 \text { to } 738) \\
187 \%(60 \text { to } 415)\end{array}$ & $\begin{array}{l}3(3 \text { to } 4) \\
3(3 \text { to } 4) \\
4(3 \text { to } 6)\end{array}$ \\
\hline & & & & RRR (CI) & \\
\hline \multirow[t]{3}{*}{$\geqslant 1$ adverse event } & $5(n=392)$ & NapS, 550 mg & $24 \%$ v $27 \%$ & $11 \%(-25$ to 37$)$ & NS \\
\hline & & & & RRI (CI) & NNH (CI) \\
\hline & $\begin{array}{l}2(n=257) \\
1(n=122)\end{array}$ & $\begin{array}{l}\text { NapS/Nap, } 440 / 400 \mathrm{mg} \\
\text { NapS/Nap, 220/200 mg }\end{array}$ & $\begin{array}{l}22 \% \vee 17 \% \\
26 \% \vee 12 \%\end{array}$ & $\begin{array}{r}32 \%(-22 \text { to } 124) \\
121 \%(-10 \text { to } 443)\end{array}$ & $\begin{array}{l}\text { NS } \\
\text { NS }\end{array}$ \\
\hline
\end{tabular}

*NS = not significant; other abbreviations defined in glossary. Weighted event rates, RBI, RRR, RRI, and Cl calculated from data in article (based on a fixed effects model). 